Article

\title{
Discovery of Novel Diterpenoids from Sinularia arborea
}

\section{Kuan-Hua Chen ${ }^{1,2}$, Chang-Feng Dai ${ }^{3}$, Tsong-Long Hwang ${ }^{4}$, Chun-Yu Chen ${ }^{5,6}$, Jan-Jung Li ${ }^{2}$, Jih-Jung Chen ${ }^{7}$, Yang-Chang Wu ${ }^{8,9,10}$, Jyh-Horng Sheu ${ }^{11,12}$, Wei-Hsien Wang ${ }^{2,11}$ and Ping-Jyun Sung ${ }^{1,2,9,11,13, *}$}

1 Graduate Institute of Marine Biotechnology, Department of Life Science and Institute of Biotechnology, National Dong Hwa University, Pingtung 944, Taiwan;

E-Mail: asdfgh0213@gmail.com

2 National Museum of Marine Biology and Aquarium, Pingtung 944, Taiwan;

E-Mails: jj@nmmba.gov.tw (J.-J.L.); whw@nmmba.gov.tw (W.-H.W.)

3 Institute of Oceanography, National Taiwan University, Taipei 106, Taiwan;

E-Mail: corallab@ntu.edu.tw

4 Graduate Institute of Natural Products, Chang Gung University, Taoyuan 333, Taiwan;

E-Mail: htl@mail.cgu.edu.tw

5 Department of Anesthesiology, Chang Gung Memorial Hospital, Taoyuan 333, Taiwan;

E-Mail: rainywoo2000@yahoo.com.tw

6 Graduate Institute of Clinical Medical Sciences, Chang Gung University, Taoyuan 333, Taiwan

7 Department of Pharmacy and Graduate Institute of Pharmaceutical Technology, Tajen University, Pingtung 907, Taiwan; E-Mail: jjchen@mail.tajen.edu.tw

8 School of Pharmacy, College of Pharmacy, China Medical University, Taichung 404, Taiwan; E-Mail: yachwu@mail.cmu.edu.tw

9 Chinese Medicine Research and Development Center, China Medical University Hospital, Taichung 404, Taiwan

${ }^{10}$ Center for Molecular Medicine, China Medical University Hospital, Taichung 404, Taiwan

11 Department of Marine Biotechnology and Resources and Division of Marine Biotechnology, Asia-Pacific Ocean Research Center, National Sun Yat-sen University, Kaohsiung 804, Taiwan; E-Mail:sheu@mail.nsysu.edu.tw

12 Doctoral Degree Program in Marine Biotechnology, National Sun Yat-sen University and Academia Sinica, Kaohsiung 804, Taiwan

13 Graduate Institute of Natural Products, Kaohsiung Medical University, Kaohsiung 807, Taiwan

* Author to whom correspondence should be addressed; E-Mail: pjsung@nmmba.gov.tw;

Tel.: +886-8-882-5037; Fax: +886-8-882-5087. 
Received: 5 November 2013; in revised form: 23 November 2013 / Accepted: 3 January 2014 /

Published: 17 January 2014

\begin{abstract}
Two novel diterpenoids, sinularbols A (1) and B (2), which were found to possess a new carbon skeleton were isolated from the soft coral Sinularia arborea. The structures of compounds $\mathbf{1}$ and $\mathbf{2}$ were elucidated by spectroscopic methods and $\mathbf{2}$ displayed a moderately inhibitory effect on the generation of superoxide anion by human neutrophils.
\end{abstract}

Keywords: sinularbol; sinularborane; diterpenoid; Sinularia arborea; superoxide anion

\title{
1. Introduction
}

Previous studies on the chemical constituents of octocorals, belonging to the genus Sinularia, have led to the isolation of a number of interesting secondary metabolites and some of these were found to possess interesting bioactivities [1,2]. In a previous study on the chemical constituents of the soft coral Sinularia arborea (phylum Cnidaria, class Anthozoa, order Alcyonacea, family Alcyoniidae) (Scheme 1) [3], collected off the waters of Taiwan, two 13-hydroxycembrane diterpenoids, arbolides A and $\mathrm{B}$ along with a trihydroxysteroid, crassarosterol $\mathrm{A}$, had been isolated [4]. In the continuing studies on this interesting species, two novel diterpenoids, sinularbols A (1) (Scheme 1 and Supplementary Figures S1-S8) and B (2) (Scheme 1 and Supplementary Figures S9-S16), which were found to possess a novel sinularborane-type carbon skeleton (3,9-cyclized cembranoid), were obtained (Scheme 1). In this paper, we describe the isolation, structure determination and bioactivity of diterpenoids $\mathbf{1}$ and 2.

Scheme 1. The soft coral Sinularia arborea and the structures of sinularbols A (1) and B (2).

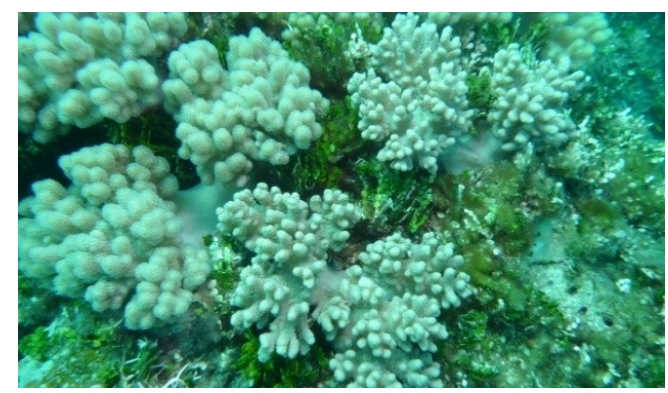

Sinularia arborea

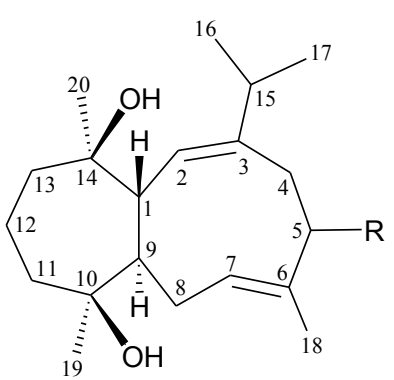

Sinularbol A (1): $\mathrm{R}=\beta-\mathrm{OH}$

Sinularbol B (2): $\mathrm{R}=\mathrm{H}$

\section{Results and Discussion}

Sinularbol A (1) was isolated as colorless oil and its molecular formula was established as $\mathrm{C}_{20} \mathrm{H}_{34} \mathrm{O}_{3}$ from a sodiated ion at $\mathrm{m} / \mathrm{z} 345$ in the ESIMS and further supported by the HRESIMS at $\mathrm{m} / \mathrm{z} 345.2404$ (calcd. for $\mathrm{C}_{20} \mathrm{H}_{34} \mathrm{O}_{3} \mathrm{Na}, 345.2406$ ) and implying four degrees of unsaturation. The presence of hydroxy groups in $\mathbf{1}$ was evidenced by a broad IR absorption at $v_{\max } 3435 \mathrm{~cm}^{-1}$. The ${ }^{13} \mathrm{C}$ spectrum of 1 
showed 20 carbon signals (Table 1), which were assigned by the assistance of DEPT spectrum to five methyls, five $\mathrm{sp}^{3}$ methylenes, four $\mathrm{sp}^{3}$ methines (including an oxymethine), two $\mathrm{sp}^{2}$ methines, two $\mathrm{sp}^{3}$ oxygenated quaternary carbons and two $\mathrm{sp}^{2}$ quaternary carbons. From the ${ }^{13} \mathrm{C}$ and ${ }^{1} \mathrm{H}$ NMR data (Table 1), two trisubstituted olefins were deduced from the signals at $\delta_{\mathrm{C}} 146.7$ (C), 137.4 (C), 127.7 $(\mathrm{CH})$ and $125.5(\mathrm{CH})$, and confirmed by two olefin proton signals at $\delta_{\mathrm{H}} 5.58(1 \mathrm{H}, \mathrm{dd}, J=6.4,6.4 \mathrm{~Hz})$ and $5.20(1 \mathrm{H}, \mathrm{d}, J=9.6 \mathrm{~Hz})$ in the ${ }^{1} \mathrm{H}$ NMR spectrum. Comparison of the ${ }^{13} \mathrm{C}$ NMR and DEPT spectra with the molecular formula indicated that there must be three exchangeable protons, requiring the presence of three hydroxy groups. From the above data, two degrees of unsaturation were accounted for and 1 must be a diterpenoid derivative with two rings.

Table 1. ${ }^{1} \mathrm{H}\left(400 \mathrm{MHz}, \mathrm{CDCl}_{3}\right)$ and ${ }^{13} \mathrm{C}\left(100 \mathrm{MHz}, \mathrm{CDCl}_{3}\right) \mathrm{NMR}$ data, ${ }^{1} \mathrm{H}-{ }^{1} \mathrm{H}$ COSY and HMBC correlations for sinularbol A (1).

\begin{tabular}{|c|c|c|c|c|c|}
\hline \multirow{2}{*}{$\frac{\text { Position }}{1}$} & \multirow{2}{*}{$\frac{\boldsymbol{\delta}_{\mathbf{H}}(\boldsymbol{J} \text { in } \mathbf{H z})}{2.45 \mathrm{dd}(11.2,9.6)}$} & \multicolumn{2}{|c|}{$\delta_{\mathrm{C}}$, Multiple } & \multirow{2}{*}{$\frac{{ }^{1} \mathbf{H}-{ }^{\mathbf{1}} \mathbf{H} \mathbf{C O S Y}}{\mathrm{H}-2, \mathrm{H}-9}$} & \multirow{2}{*}{$\begin{array}{c}\text { НМВС } \\
\text { C-2, }-3,-9,-10,-14\end{array}$} \\
\hline & & 49.9 & $\mathrm{CH}$ & & \\
\hline 2 & $5.20 \mathrm{~d}(9.6)$ & 125.5 & $\mathrm{CH}$ & H-1 & $\mathrm{C}-1,-4,-9,-15$ \\
\hline 3 & & 146.7 & $\mathrm{C}$ & & \\
\hline \multirow[t]{2}{*}{4} & $2.12 \mathrm{dd}(12.8,2.8)$ & 38.3 & $\mathrm{CH}_{2}$ & H-5 & $C-2,-3,-5,-6,-15$ \\
\hline & $2.94 \mathrm{dd}(12.8,11.2)$ & & & & \\
\hline 5 & $4.03 \mathrm{ddd}(11.2,2.8,2.8)$ & 76.0 & $\mathrm{CH}$ & $\mathrm{H}_{2}-4, \mathrm{OH}-5$ & n.o. ${ }^{a}$ \\
\hline 6 & & 137.4 & $\mathrm{C}$ & & \\
\hline 7 & $5.58 \mathrm{dd}(6.4,6.4)$ & 127.7 & $\mathrm{CH}$ & $\mathrm{H}_{2}-8$ & C-5, -18 \\
\hline 8 & $2.16 \mathrm{~m} ; 2.27 \mathrm{~m}$ & 22.4 & $\mathrm{CH}_{2}$ & H-7, H-9 & C-7, -10 \\
\hline 9 & $1.97 \mathrm{~m}$ & 56.6 & $\mathrm{CH}$ & $\mathrm{H}-1, \mathrm{H}_{2}-8$ & n.o. \\
\hline 10 & & 74.7 & $\mathrm{C}$ & & \\
\hline 11 & $1.62 \mathrm{~m} ; 1.98 \mathrm{~m}$ & 33.9 & $\mathrm{CH}_{2}$ & $\mathrm{H}_{2}-12$ & C-9, -10 \\
\hline 12 & $1.34 \mathrm{~m} ; 1.66 \mathrm{~m}$ & 23.4 & $\mathrm{CH}_{2}$ & $\mathrm{H}_{2}-11, \mathrm{H}_{2}-13$ & n.o. \\
\hline 13 & $1.68-1.75 \mathrm{~m}$ & 39.5 & $\mathrm{CH}_{2}$ & $\mathrm{H}_{2}-12$ & $C-1,-12,-14$ \\
\hline 14 & & 81.5 & $\mathrm{C}$ & & \\
\hline 15 & $2.30 \mathrm{~m}$ & 34.6 & $\mathrm{CH}$ & $\mathrm{H}_{3}-16, \mathrm{H}_{3}-17$ & $C-2,-3,-4,-16,-17$ \\
\hline 16 & $1.09 \mathrm{~d}(6.8)$ & 24.1 & $\mathrm{CH}_{3}$ & H-15 & C- $-15,-17$ \\
\hline 17 & $1.09 \mathrm{~d}(6.8)$ & 24.2 & $\mathrm{CH}_{3}$ & H-15 & $C-15,-17$ \\
\hline 18 & $1.78 \mathrm{~s}$ & 12.7 & $\mathrm{CH}_{3}$ & & $C-5,-6,-7$ \\
\hline 19 & $1.16 \mathrm{~s}$ & 31.3 & $\mathrm{CH}_{3}$ & & $C-9,-10,-11$ \\
\hline 20 & $1.09 \mathrm{~s}$ & 22.2 & $\mathrm{CH}_{3}$ & & $C-1,-13,-14$ \\
\hline OH-5 & $1.53 \mathrm{~d}(2.8)$ & & & H-5 & n.o. \\
\hline $\mathrm{OH}-10$ & $2.08 \mathrm{~s}$ & & & & C-9, $-10,-19$ \\
\hline $\mathrm{OH}-14$ & $2.18 \mathrm{~s}$ & & & & C-13, -14 \\
\hline
\end{tabular}

${ }^{a}$ n.o. is not observed.

From the ${ }^{1} \mathrm{H}-{ }^{1} \mathrm{H}$ COSY spectrum of 1 , the separate spin systems of $\mathrm{H}_{2}-4 / \mathrm{H}-5$ and $\mathrm{H}-7 / \mathrm{H}_{2}-8 / \mathrm{H}-9 /$ $\mathrm{H}-1 / \mathrm{H}-2$ were differentiated. These data, together with the HMBC correlations among H-1/C-2, $-3,-9$; $\mathrm{H}-2 / \mathrm{C}-1,-4,-9 ; \mathrm{H}_{2}-4 / \mathrm{C}-2,-3,-5,-6 ; \mathrm{H}-7 / \mathrm{C}-5 ; \mathrm{H}-8 / \mathrm{C}-7$, established the connectivity from $\mathrm{C}-1$ to $\mathrm{C}-9$ in the nine-membered ring (Table 1). The 1,4-dimethylcycloheptane ring, which is fused to the nine-membered ring at $\mathrm{C}-1$ and $\mathrm{C}-9$, was elucidated by the $\mathrm{HMBC}$ correlations between $\mathrm{H}-1 / \mathrm{C}-10,-14$; $\mathrm{H}_{2}-8 / \mathrm{C}-10 ; \mathrm{H}_{2}-11 / \mathrm{C}-9 ; \mathrm{H}_{2}-13 / \mathrm{C}-1 ; \mathrm{H}_{3}-19 / \mathrm{C}-9,-10,-11 ; \mathrm{H}_{3}-20 / \mathrm{C}-1,-13,-14 ;$ and OH-10/C-9. 
The isopropyl group was established by the ${ }^{1} \mathrm{H}-{ }^{1} \mathrm{H}$ COSY correlations between $\mathrm{H}-15 / \mathrm{H}_{3}-16\left(\mathrm{H}_{3}-17\right)$ and this group at $\mathrm{C}-3$ from the HMBC correlations among $\mathrm{H}-2 / \mathrm{C}-15 ; \mathrm{H}_{2}-4 / \mathrm{C}-15$; and $\mathrm{H}-15 / \mathrm{C}-2,-3,-4$. A vinyl methyl at $\mathrm{C}-11$ was confirmed by the $\mathrm{HMBC}$ correlations between $\mathrm{H}_{3}-18 / \mathrm{C}-5,-6,-7$ and $\mathrm{H}-7 / \mathrm{C}-18$. The hydroxy proton signal at $\delta_{\mathrm{H}} 1.53(1 \mathrm{H}, \mathrm{d}, J=2.8 \mathrm{~Hz}, \mathrm{OH}-5)$ was revealed by its ${ }^{1} \mathrm{H}-{ }^{1} \mathrm{H}$ COSY correlation to $\delta_{\mathrm{H}} 4.03(1 \mathrm{H}, \mathrm{d}, J=11.2,2.8,2.8 \mathrm{~Hz}, \mathrm{H}-5)$, indicating its attachment to C-5. These data, together with the HMBC correlations between $\mathrm{OH}-10\left(\delta_{\mathrm{H}} 2.08\right) / \mathrm{C}-9,-10,-19$ and $\mathrm{OH}-14$ $\left(\delta_{\mathrm{H}} 2.18\right) / \mathrm{C}-13,-14$, unambiguously established the molecular framework of $\mathbf{1}$.

The relative configuration of $\mathbf{1}$ was elucidated from the interactions observed in a NOESY experiment and was found to be compatible with that of 1 offered by computer modeling (Scheme 2) [5] and that obtained from vicinal proton coupling constant analysis. Because of the $\beta$-orientation of $\mathrm{H}-1$, and this proton correlated with one of the methylene protons at C-4 $\left(\delta_{\mathrm{H}} 2.94\right)$, and therefore it was assigned as $\mathrm{H}-4 \beta$ and the other C-4 proton $\left(\delta_{\mathrm{H}} 2.12\right)$ as $\mathrm{H}-4 \alpha$. H-5 correlated with $\mathrm{H}-4 \alpha$, but not with $\mathrm{H}-4 \beta$, and a large coupling constant was recorded between these $\mathrm{H}-5$ and $\mathrm{H}-4 \beta(J=11.2 \mathrm{~Hz})$, indicated that the 5-hydroxy group was $\beta$-oriented. Large coupling constants were detected between $\mathrm{H}-1 / \mathrm{H}-2(J=9.6 \mathrm{~Hz})$ and $\mathrm{H}-1 / \mathrm{H}-9(J=11.2 \mathrm{~Hz})$ and there is no correlation was found between $\mathrm{H}-1 / \mathrm{H}-2$ and $\mathrm{H}-1 / \mathrm{H}-9$, indicating that the dihedral angles between $\mathrm{H}-1 / \mathrm{H}-2$ and $\mathrm{H}-1 / \mathrm{H}-9$ are approximately $180^{\circ}$, respectively, and $\mathrm{H}-9$ should be $\alpha$-oriented. This structure was further supported by a correlation between $\mathrm{H}-2$ and H-9. $\mathrm{H}_{3}-20$ showed a correlation with $\mathrm{H}-2$, but not with $\mathrm{H}-1$, demonstrating the $\alpha$-orientation of Me-20. The C-19 methyl showed a correlation with $\mathrm{H}-9$, indicating that the hydroxy group at $\mathrm{C}-10$ was $\beta$-oriented. Correlations between $\mathrm{H}-5 / \mathrm{H}-7$ and $\mathrm{H}-4 \alpha / \mathrm{H}-15$, as well as the lack of correlation between $\mathrm{H}-7 / \mathrm{H}_{3}-18$ and $\mathrm{H}-2 / \mathrm{H}_{2}-4$, reflected the $E$ geometry of the double bonds at C-2/3 and C-6/7. Based on the above findings, the structure of 1 was elucidated and the chiral carbons for 1 were assigned as $1 R^{*}$, $5 R^{*}, 9 R^{*}, 10 S^{*}$ and $14 R^{*}$.

Scheme 2. The computer-generated model of 1 using MM2 force field calculations and the calculated distances $(\AA)$ between selected protons with key NOESY correlations.

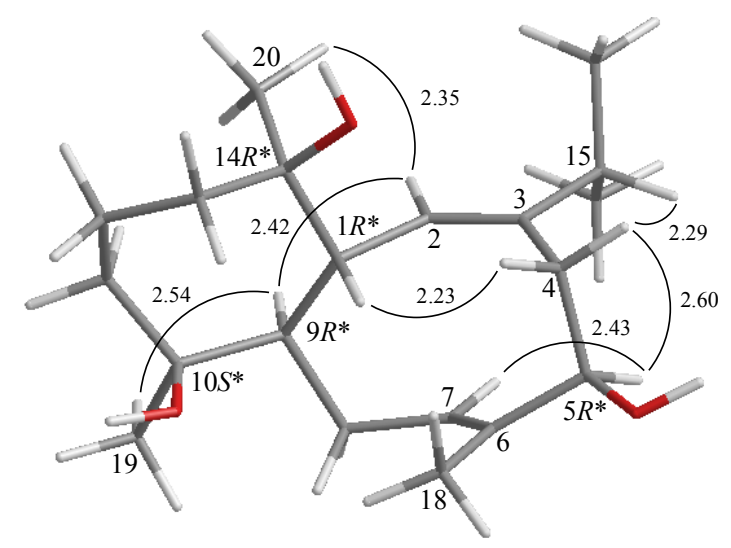

The new sinularborane 2 (sinularbol B) was isolated as colorless oil and its molecular formula $\mathrm{C}_{20} \mathrm{H}_{34} \mathrm{O}_{2}$ was established by HRESIMS ( $\mathrm{m} / z$ 329.2453, calcd. for $\mathrm{C}_{20} \mathrm{H}_{34} \mathrm{O}_{2} \mathrm{Na}$, 329.2456). The IR spectrum of 2 showed a broad band at $3447 \mathrm{~cm}^{-1}$, consistent with the presence of hydroxy groups. It was found that the ${ }^{1} \mathrm{H}$ and ${ }^{13} \mathrm{C}$ NMR data of 2 were similar to those of $\mathbf{1}$, except that the signals corresponding to the $\mathrm{C}-5$, a hydroxy-bearing oxymethine group in $\mathbf{1}\left(\delta_{\mathrm{H}} 4.03,1 \mathrm{H}\right.$, ddd, $J=11.2,2.8$, 
$\left.2.8 \mathrm{~Hz} ; \delta_{\mathrm{C}} 76.0, \mathrm{CH}\right)$ were replaced by a methylene group in $2\left(\delta_{\mathrm{H}} 1.88,1 \mathrm{H}, \mathrm{m} ; 2.22,1 \mathrm{H}, \mathrm{m} ; \delta_{\mathrm{C}} 35.9\right.$, $\mathrm{CH}_{2}$ ) (Table 2). The ${ }^{1} \mathrm{H}-{ }^{1} \mathrm{H}$ COSY and HMBC correlations observed fully supported the locations of functional groups (Table 2), and hence sinularbol B (2) was assigned as the structure 2 with the same relative stereochemistry as in sinularbol A (1) because for the chiral carbons that $\mathbf{2}$ had in common with 1 and the relative configurations of 2 were assigned as $1 R^{*}, 9 R^{*}, 10 S^{*}$ and $14 R^{*}$. The ${ }^{1} \mathrm{H}$ and ${ }^{13} \mathrm{C}$ NMR chemical shifts and proton coupling constants match well, and are further supported by a NOESY experiment.

Table 2. ${ }^{1} \mathrm{H}\left(400 \mathrm{MHz}, \mathrm{CDCl}_{3}\right)$ and ${ }^{13} \mathrm{C}\left(100 \mathrm{MHz}, \mathrm{CDCl}_{3}\right) \mathrm{NMR}$ data, ${ }^{1} \mathrm{H}-{ }^{1} \mathrm{H}$ COSY and HMBC correlations for sinularbol B (2).

\begin{tabular}{|c|c|c|c|c|c|}
\hline \multirow{2}{*}{$\frac{\text { Position }}{1}$} & \multirow{2}{*}{$\frac{\boldsymbol{\delta}_{\mathbf{H}}(\boldsymbol{J} \text { in Hz })}{2.54 \mathrm{dd}(11.2,9.6)}$} & \multicolumn{2}{|c|}{$\delta_{\mathrm{C}}$, Multiple } & \multirow{2}{*}{$\begin{array}{c}{ }^{\mathbf{1}} \mathbf{H}-{ }^{1} \mathbf{H} \text { COSY } \\
\text { H-2, H-9 }\end{array}$} & \multirow{2}{*}{$\frac{\text { НМВС }}{\mathrm{C}-2,-3,-9,-10,-14,-20}$} \\
\hline & & 50.2 & $\mathrm{CH}$ & & \\
\hline 2 & $5.19 \mathrm{dd}(9.6)$ & 124.0 & $\mathrm{CH}$ & H-1 & C- $1,-4,-9,-15$ \\
\hline 3 & & 149.0 & $\mathrm{C}$ & & \\
\hline 4 & $\begin{array}{c}1.99 \mathrm{~m} \\
2.72 \mathrm{ddd}(13.2,13.2,2.8)\end{array}$ & 29.5 & $\mathrm{CH}_{2}$ & $\mathrm{H}_{2}-5$ & $C-2,-3,-5,-6,-15$ \\
\hline 5 & $1.88 \mathrm{~m} ; 2.22 \mathrm{~m}$ & 35.9 & $\mathrm{CH}_{2}$ & $\mathrm{H}_{2}-4$ & $C-3,-4,-6,-7,-18$ \\
\hline 6 & & 134.8 & $\mathrm{C}$ & & \\
\hline 7 & $5.32 \mathrm{dd}(5.6,5.6)$ & 127.7 & $\mathrm{CH}$ & $\mathrm{H}_{2}-8$ & n.o. ${ }^{a}$ \\
\hline 8 & $2.08 \mathrm{~m} ; 2.30 \mathrm{~m}$ & 22.8 & $\mathrm{CH}_{2}$ & $\mathrm{H}-7, \mathrm{H}-9$ & $\mathrm{C}-7,-10$ \\
\hline 9 & $1.97 \mathrm{~m}$ & 56.6 & $\mathrm{CH}$ & $\mathrm{H}-1, \mathrm{H}_{2}-8$ & n.o. \\
\hline 10 & & 74.7 & $\mathrm{C}$ & & \\
\hline 11 & $1.59 \mathrm{~m} ; 1.88 \mathrm{~m}$ & 34.1 & $\mathrm{CH}_{2}$ & $\mathrm{H}_{2}-12$ & C-9, $-12,-19$ \\
\hline 12 & $1.35 \mathrm{~m} ; 1.66 \mathrm{~m}$ & 23.3 & $\mathrm{CH}_{2}$ & $\mathrm{H}_{2}-11, \mathrm{H}_{2}-13$ & C-10 \\
\hline 13 & $1.68-1.77 \mathrm{~m}$ & 39.2 & $\mathrm{CH}_{2}$ & $\mathrm{H}_{2}-12$ & $C-1,-14,-20$ \\
\hline 14 & & 81.5 & $\mathrm{C}$ & & \\
\hline 15 & $2.27 \mathrm{~m}$ & 33.2 & $\mathrm{CH}$ & $\mathrm{H}_{3}-16, \mathrm{H}_{3}-17$ & $C-2,-3,-16,-17$ \\
\hline 16 & $1.06 \mathrm{~d}(6.8)$ & 24.1 & $\mathrm{CH}_{3}$ & H-15 & $\mathrm{C}-3,-15,-17$ \\
\hline 17 & $1.09 \mathrm{~d}(6.8)$ & 24.4 & $\mathrm{CH}_{3}$ & H-15 & C-3, $-15,-16$ \\
\hline 18 & $1.70 \mathrm{~s}$ & 18.2 & $\mathrm{CH}_{3}$ & & $C-5,-6,-7$ \\
\hline 19 & $1.51 \mathrm{~s}$ & 31.6 & $\mathrm{CH}_{3}$ & & C-9, $-10,-11$ \\
\hline 20 & $1.08 \mathrm{~s}$ & 22.1 & $\mathrm{CH}_{3}$ & & C- $1,-13,-14$ \\
\hline
\end{tabular}

The in vitro anti-inflammatory effects of compounds $\mathbf{1}$ and $\mathbf{2}$ were examined and $\mathbf{2}$ displayed a moderately inhibitory effect on the generation of superoxide anion by human neutrophils (Table 3) [6].

Table 3. Inhibitory effects of diterpenoids 1 and $\mathbf{2}$ on the generation of superoxide anion and the release of elastase by human neutrophils in response to FMLP/CB.

\begin{tabular}{cccc}
\hline \multirow{2}{*}{ Compound } & Superoxide anion & & Elastase release \\
\cline { 2 - 3 } & $\mathbf{I n h} \%$ & $\mathbf{I n h \%}$ \\
\hline $\mathbf{1}$ & $7.37 \pm 1.98^{*}$ & & $11.71 \pm 1.35 * *$ \\
$\mathbf{2}$ & $23.94 \pm 6.35 *$ & $6.54 \pm 3.54$ \\
\hline
\end{tabular}

Percentage of inhibition (Inh\%) at a concentration of $10 \mu \mathrm{g} / \mathrm{mL}$. The results are presented as mean \pm S.E.M. $(n=3) * p<0.05 ; * * * p<0.001$, compared with the control value. 


\section{Experimental Section}

\subsection{General Experimental Procedures}

Optical rotations were measured at a Jasco P-1010 digital polarimeter (Japan Spectroscopic Corporation, Tokyo, Japan). Infrared spectra were recorded on a Varian Diglab FTS 1000 FT-IR spectrometer (Varian Inc., Palo Alto, CA, USA); peaks are reported in $\mathrm{cm}^{-1}$. NMR spectra were recorded on a Varian Mercury Plus 400 NMR spectrometer (Varian Inc., Palo Alto, CA, USA) using the residual $\mathrm{CHCl}_{3}$ signal $\left(\delta_{\mathrm{H}} 7.26 \mathrm{ppm}\right)$ as the internal standard for ${ }^{1} \mathrm{H} \mathrm{NMR}$ and $\mathrm{CDCl}_{3}\left(\delta_{\mathrm{C}} 77.1 \mathrm{ppm}\right)$ for ${ }^{13} \mathrm{C}$ NMR. Coupling constants $(J)$ are given in Hz. ESIMS and HRESIMS were recorded using a Bruker APEX II FT mass spectrometer (Bruker, Bremen, Germany). Column chromatography was performed on silica gel (230-400 mesh, Merck, Darmstadt, Germany). TLC was carried out on precoated Kieselgel $60 \mathrm{~F}_{254}\left(0.25 \mathrm{~mm}\right.$, Merck); spots were visualized by spraying with $10 \% \mathrm{H}_{2} \mathrm{SO}_{4}$ solution followed by heating. The normal phase HPLC (NP-HPLC) was performed using a system comprised of a Hitachi L-7110 pump (Hitachi Ltd. Tokyo, Japan) and a Rheodyne 7725 injection port (Rheodyne LLC. Rohnert Park, CA, USA). A normal phase column (Supelco Ascentis ${ }^{\circledR}$ Si Cat \#: 581515-U, $25 \mathrm{~cm} \times 21.2 \mathrm{~mm}, 5 \mu \mathrm{m}$, Sigma-Aldrich. Com. St. Louis, MO, USA) was used for NP-HPLC. The reverse phase HPLC (NP-HPLC) was performed using a system comprised of a Hitachi L-7100 pump (Hitachi Ltd., Tokyo, Japan), a Hitachi L-2455 photodiode array detector (Hitachi Ltd., Tokyo, Japan), a Rheodyne 7725 injection port (Rheodyne LLC., Rohnert Park, CA, USA) and a Varian Polaris $5 \mathrm{C}-18$-A column $(25 \mathrm{~cm} \times 10 \mathrm{~mm}, 5 \mu \mathrm{m})$.

\subsection{Animal Material}

Specimens of the octocoral Sinularia arborea were collected by hand using SCUBA equipment off the coast of southern Taiwan on October, 2012, and stored at $-20{ }^{\circ} \mathrm{C}$ until extraction. A voucher specimen (NMMBA-TWSC-1200X) was deposited in the National Museum of Marine Biology and Aquarium, Taiwan.

\subsection{Extraction and Isolation}

Specimens of the soft coral Sinularia arborea (wet weight $1.6 \mathrm{~kg}$, dry weight $576 \mathrm{~g}$ ) were minced and extracted with ethyl acetate (EtOAc). The EtOAc extract left after removal of the solvent (12.5 g) was separated by silica gel and eluted using a mixture of $n$-hexane/EtOAc in a stepwise fashion from 100:1-pure EtOAc to yield 11 fractions A-K. Fraction I was chromatographed on silica gel and eluted using a mixture of $n$-hexane and acetone (6:1/4:1/2:1/pure acetone) to yield 25 subfractions I1-I25. Fraction I12 was repurified by NP-HPLC, using a mixture of $n$-hexane and acetone (4:1) to yield 46 subfractions I12-1-I12-46. Fraction I12-43 was repurified by NP-HPLC, using a mixture of $n$-hexane and acetone (4:1, flow rate: $1.0 \mathrm{~mL} / \mathrm{min})$ to yield $1\left(0.7 \mathrm{mg}, t_{\mathrm{R}}=73 \mathrm{~min}\right)$. Fraction $\mathrm{E}$ was separated by NP-HPLC, using a mixture of dichloromethane and methanol (90:1) to yield 26 subfractions E1-E26. E20 was repurified by NP-HPLC, using a mixture of $n$-hexane and acetone $(10: 1)$ to yield 9 subfractions E20A-E20I. Fraction E20F was repurified by RP-HPLC, using a mixture of methanol and water (84:16) to yield 14 subfractions E20F1-E20F14. Fraction E20F2 was further 
separated by RP-HPLC, using a mixture of acetonitrile and water (4:1, flow rate: $1.0 \mathrm{~mL} / \mathrm{min})$ to yield $2\left(0.9 \mathrm{mg}, t_{\mathrm{R}}=31 \mathrm{~min}\right)$.

Sinularbol A (1): colorless oil; $[\alpha]_{\mathrm{D}}^{24}-47\left(c 0.04, \mathrm{CHCl}_{3}\right)$; IR (neat) $v_{\max } 3435 \mathrm{~cm}^{-1}$; ${ }^{1} \mathrm{H}(400 \mathrm{MHz}$, $\left.\mathrm{CDCl}_{3}\right)$ and ${ }^{13} \mathrm{C}\left(100 \mathrm{MHz}, \mathrm{CDCl}_{3}\right) \mathrm{NMR}$ data, see Table 1; ESIMS: $m / z 345[\mathrm{M}+\mathrm{Na}]^{+}$; HRESIMS: $m / z 345.2404$ (calcd. for $\mathrm{C}_{20} \mathrm{H}_{34} \mathrm{O}_{3} \mathrm{Na}, 345.2406$ ).

Sinularbol B (2): colorless oil; $[\alpha]_{\mathrm{D}}^{23}-8\left(c 0.05, \mathrm{CHCl}_{3}\right)$; IR (neat) $v_{\max } 3447 \mathrm{~cm}^{-1} ;{ }^{1} \mathrm{H}(400 \mathrm{MHz}$, $\left.\mathrm{CDCl}_{3}\right)$ and ${ }^{13} \mathrm{C}\left(100 \mathrm{MHz}, \mathrm{CDCl}_{3}\right) \mathrm{NMR}$ data, see Table 2; ESIMS: $m / z 327[\mathrm{M}+\mathrm{Na}]^{+}$; HRESIMS: $m / z 329.2453$ (calcd. for $\mathrm{C}_{20} \mathrm{H}_{34} \mathrm{O}_{2} \mathrm{Na}, 329.2456$ ).

\subsection{Generation of Superoxide Anions and Release of Elastase by Human Neutrophils}

Human neutrophils were obtained by means of dextran sedimentation and Ficoll centrifugation. Measurements of superoxide anion generation and elastase release were carried out according to previously described procedures [7-13]. Briefly, superoxide anion production was assayed by monitoring the superoxide dismutase-inhibitable reduction of ferricytochrome $c$. Elastase release experiments were performed using $\mathrm{MeO}$-Suc-Ala-Ala-Pro-Valp-nitroanilide as the elastase substrate.

\section{Conclusions}

Octocorals have proven to be rich sources of cyclized cembranoid analogues [14-16]. In our continuing investigation on the chemical constituents of marine invertebrates collected off the waters of Taiwan, two novel diterpenoids, sinularbols A (1) and B (2), which were found to possess a novel sinularborane-type carbon skeleton, were isolated from the soft coral Sinularia arborea and 2 was found to show anti-inflammatory activity. It is noteworthy to mention that metabolites $\mathbf{1}$ and $\mathbf{2}$ represent the first 3,9-cyclized cembranoid (sinularborane skeleton) derivatives.

\section{Acknowledgments}

This research was supported by grants from the National Dong Hwa University; the Chang Gung Memorial Hospital (Grant No. CMRPG3C0141); the National Museum of Marine Biology and Aquarium; the Division of Marine Biotechnology, Asia-Pacific Ocean Research Center, National Sun Yat-sen University; and the National Science Council (Grant No. NSC 102-2325-B-291-001 and 101-2320-B-291-001-MY3), Taiwan, awarded to Ping-Jyun Sung.

\section{Conflicts of Interest}

The authors declare no conflict of interest.

\section{References and Notes}

1. Chen, W.-T.; Li, Y.; Guo, Y.-W. Terpenoids of Sinularia soft corals: Chemistry and bioactivity. Acta Pharm. Sin. B 2012, 2, 227-237. 
2. Rocha, J.; Peixe, L.; Gomes, N.C.M.; Calado, R. Cnidarians as a source of new marine bioactive compounds-An overview of the last decade and future steps for bioprospecting. Mar. Drugs 2011, 9, 1860-1886.

3. Verseveldt, J. Octocorallia from North-Western Madagascar (Part II). Zool. Verh. 1971, 117, $1-73$.

4. Chen, K.-H.; Dai, C.-F.; Lu, M.-C.; Li, J.-J.; Chen, J.-J.; Chang, Y.-C.; Su, Y.-D.; Wang, W.-H.; Sung, P.-J. Secondary metabolites from the soft coral Sinularia arborea. Mar. Drugs 2013, 11, 3372-3380.

5. Allinger, N.L. Conformational analysis. 130. MM2. A hydrocarbon force field utilizing $V 1$ and $V 2$ torsional terms. J. Am. Chem. Soc. 1977, 99, 8127-8134.

6. In the in vitro anti-inflammatory bioassay, the inhibitory effects on the generation of superoxide anion and the release of elastase by activated neutrophils were used as indicators. For significant activity of pure compounds, an inhibition rate $\geq 50 \%$ is required (inhibition rate $\leq 10 \%$, not active; $20 \% \geq$ inhibition rate $\geq 10 \%$, weakly anti-inflammatory; $50 \% \geq$ inhibition rate $\geq 20 \%$, modestly anti-inflammatory).

7. Yu, H.-P.; Hsieh, P.-W.; Chang, Y.-J.; Chung, P.-J.; Kuo, L.-M.; Hwang, T.-L. 2-(2-Fluoro-benzamido)benzoate ethyl ester (EFB-1) inhibits superoxide production by human neutrophils and attenuates hemorrhagic shock-induced organ dysfunction in rats. Free Radic. Biol. Med. 2011, 50, 1737-1748.

8. Hwang, T.-L.; Wang, C.-C.; Kuo, Y.-H.; Huang, H.-C.; Wu, Y.-C.; Kuo, L.-M.; Wu, Y.-H. The hederagenin saponin SMG-1 is a natural FMLP receptor inhibitor that suppresses human neutrophil activation. Biochem. Pharmacol. 2010, 80, 1190-1200.

9. Hwang, T.-L.; Su, Y.-C.; Chang, H.-L.; Leu, Y.-L.; Chung, P.-J.; Kuo, L.-M.; Chang, Y.-J. Suppression of superoxide anion and elastase release by $\mathrm{C}_{18}$ unsaturated fatty acids in human neutrophils. J. Lipid Res. 2009, 50, 1395-1408.

10. Hwang, T.-L.; Li, G.-L.; Lan, Y.-H.; Chia, Y.-C.; Hsieh, P.-W.; Wu, Y.-H.; Wu, Y.-C. Potent inhibition of superoxide anion production in activated human neutrophils by isopedicin, a bioactive component of the Chinese medicinal herb Fissistigma oldhamii. Free Radic. Biol. Med. 2009, 46, 520-528.

11. Hwang, T.-L.; Leu, Y.-L.; Kao, S.-H.; Tang, M.-C.; Chang, H.-L. Viscolin, a new chalcone from Viscum coloratum, inhibits human neutrophil superoxide anion and elastase release via a cAMP-dependent pathway. Free Radic. Biol. Med. 2006, 41, 1433-1441.

12. Hwang, T.-L.; Yeh, S.-H.; Leu, Y.-L.; Chern, C.-Y.; Hsu, H.-C. Inhibition of superoxide anion and elastase release in human neutrophils by 3 '-isopropoxychalcone via a cAMP-dependent pathway. Br. J. Pharmacol. 2006, 148, 78-87.

13. Hwang, T.-L.; Hung, H.-W.; Kao, S.-H.; Teng, C.-M.; Wu, C.-C.; Cheng, S.J.-S. Soluble guanylyl cyclase activator YC-1 inhibits human neutrophil functions through a cGMP-independent but cAMP-dependent pathway. Mol. Pharmacol. 2003, 64, 1419-1427.

14. Wahlberg, I.; Eklund, A.-M. Cyclized cembranoids of natural occurrence. Prog. Chem. Org. Nat. Prod. 1992, 60, 1-141.

15. Berrue, F.; Kerr, R.G. Diterpenes from gorgonian corals. Nat. Prod. Rep. 2009, 26, 681-710. 
16. Blunt, J.W.; Copp, B.R.; Keyzers, R.A.; Munro, M.H.G.; Prinsep, M.R. Marine natural products. Nat. Prod. Rep. 2013, 30, 237-323.

(C) 2014 by the authors; licensee MDPI, Basel, Switzerland. This article is an open access article distributed under the terms and conditions of the Creative Commons Attribution license (http://creativecommons.org/licenses/by/3.0/). 